Proc. Indian Acad. Sci. (Chem. Sci.), Vol. 107, No. 2, April 1995, pp. 87-94.

(c) Printed in India.

\title{
Catalytic decomposition of benzyl alcohol using copper aluminate
}

\author{
VIJAYASRI SRINIVASAN* and N NAGARAJU \\ Department of Chemistry, St. Joseph's College, Bangalore 560001 , India \\ MS received 1 June 1994; revised 17 September 1994
}

\begin{abstract}
Copper aluminate prepared by co-precipitation method catalyses the decomposition of benzyl alcohol forming benzaldehyde, toluene, water and hydrogen. Single phase formation of copper aluminate has been identified using $X$-ray diffraction technique. Copper aluminate acts as a dehydrogenating catalyst forming benzaldehyde. Toluene formation may be due to hydrogenolysis of benzyl alcohol. The effect of temperature and contact time has been studied. Energy of activation has been calculated from the Arrbenius plot. Partial pressure studies have been conducted using benzaldehyde to study the mechanistic aspects. Addition of benzaldehyde inhibits dehydrogenation of benzyl alcohol. Desorption of benzaldehyde can therefore be considerod the rate-determining step.
\end{abstract}

Keywords Catalytic decomposition; benzyl alcohol; catalysis by copper aluminate.

\section{Introduction}

Mixed oxides crystallizing in spinel form serve as potential catalysts for the oxidation of hydrocarbons (Kushnerev et al 1961; Zanderighi et al 1974), carbon monoxide (Paetour and Reikert 1979; Vishwanathan et al 1979; Piperov and Mekhand Zhiev 1987) and dehydrogenation of alcohols (Massoth and Scarpiello 1971; Krishnaswamy and Chokkalingam 1982). Copper aluminate, a spinel, has been used for dehydrogenation of isopropyl alcohol (Ramalingam and Swamy 1978) and benzhydrol (Venkatasubramanian 1979). Transfer hydrogenation reactions from alcohols to ketones occur when nickel aluminate is used as the catalyst, this reaction however does not take place when copper aluminate is used (Venkatasubramanian 1979). Cobalt aluminate is used as a dehydration catalyst (Ramalingam and Swamy 1978). The present study deals with the decomposition of benzyl alcohol using copper aluminate as the catalyst. The kinetic and mechanistic aspects have also been studied.

\section{Experimental}

\subsection{Preparation of catalyst}

The catalyst copper aluminate is prepared by co-precipitation method (Murthy 1991). Stoichiometric amounts of copper nitrate and aluminium nitrate are taken and their hydroxides are precipitated, dried and calcined in air at $950^{\circ} \mathrm{C}$ for $6 \mathrm{~h}$. The unreacted

\footnotetext{
* For correspondence
} 
copper oxide is removed by repeated washing with $1 \mathrm{M}$ ammonium carbonate solution (Ketchik et al 1980).

\subsection{Characterization of catalyst}

The catalyst was characterized by X-ray diffraction technique using JEOL-JDX-8P $X$-ray powder diffractometer. The sample shows single phase copper aluminate with no impurities of copper oxide. X-ray diffraction data (figure 1, table 1) agree well with the reported values given in JCPDS file.

The surface area of the catalyst is determined using BET surface area analyser. The surface area is found to be $5.9 \mathrm{~m}^{2} / \mathrm{g}$. EDAX (Energy dispersive analysis using X-rays) studies have shown that copper and aluminium are in the ratio of $1: 2$.

\subsection{Apparatus for reaction studies}

A flow-type reactor unit (figure 2) working at atmospheric pressure is used for the catalytic studies (Pandao et al 1962). The apparatus is flushed with nitrogen for 10 minutes at the beginning of every run to obtain an inert atmosphere. The reactant is fed into the reactor by means of a motor-driven syringe pump (Electronics Engineering Corporation, Madras) for accurate control and metering of the flow rate. The reactor containing the catalyst is kept inside a furnace which is heated electrically. The temperature of the catalyst was controlled using an on-off temperature controllercum-indicator (Heatcon Instruments, Bangalore) within $\pm 2^{\circ} \mathrm{C}$. The effluent stream from the reactor is cooled by means of a double-walled Leibig's condenser and the liquid products are collected in a trap which is cooled with ice. The gaseous products are collected in a gas burette.

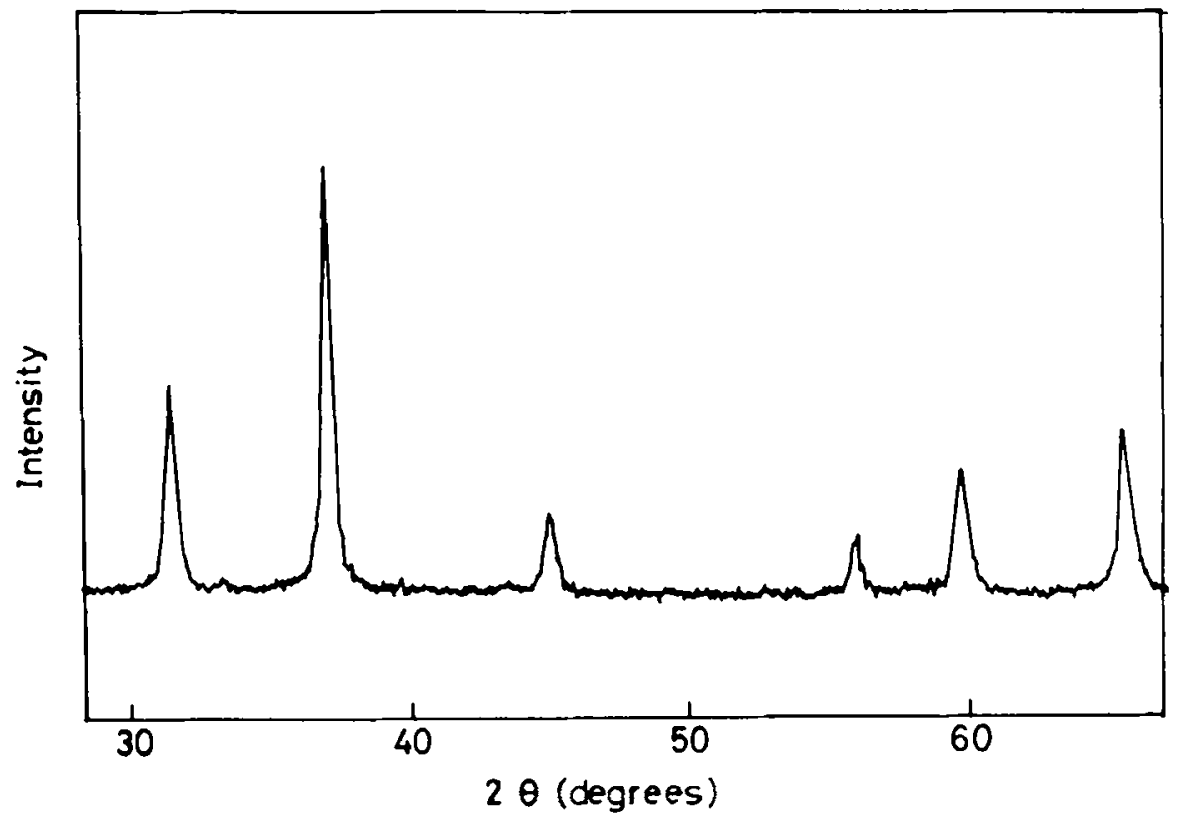

Figure 1. X-ray diffraction pattern of copper aluminate. 
Table 1. X-ray diffraction data of copper aluminate.

\begin{tabular}{llllllll}
\hline$d$ Values & 2.844 & 2.427 & 2.015 & 1.646 & 1.552 & 1.426 & 1.231 \\
Relative intensity & 49 & 100 & 24 & 21 & 38 & 45 & 18
\end{tabular}

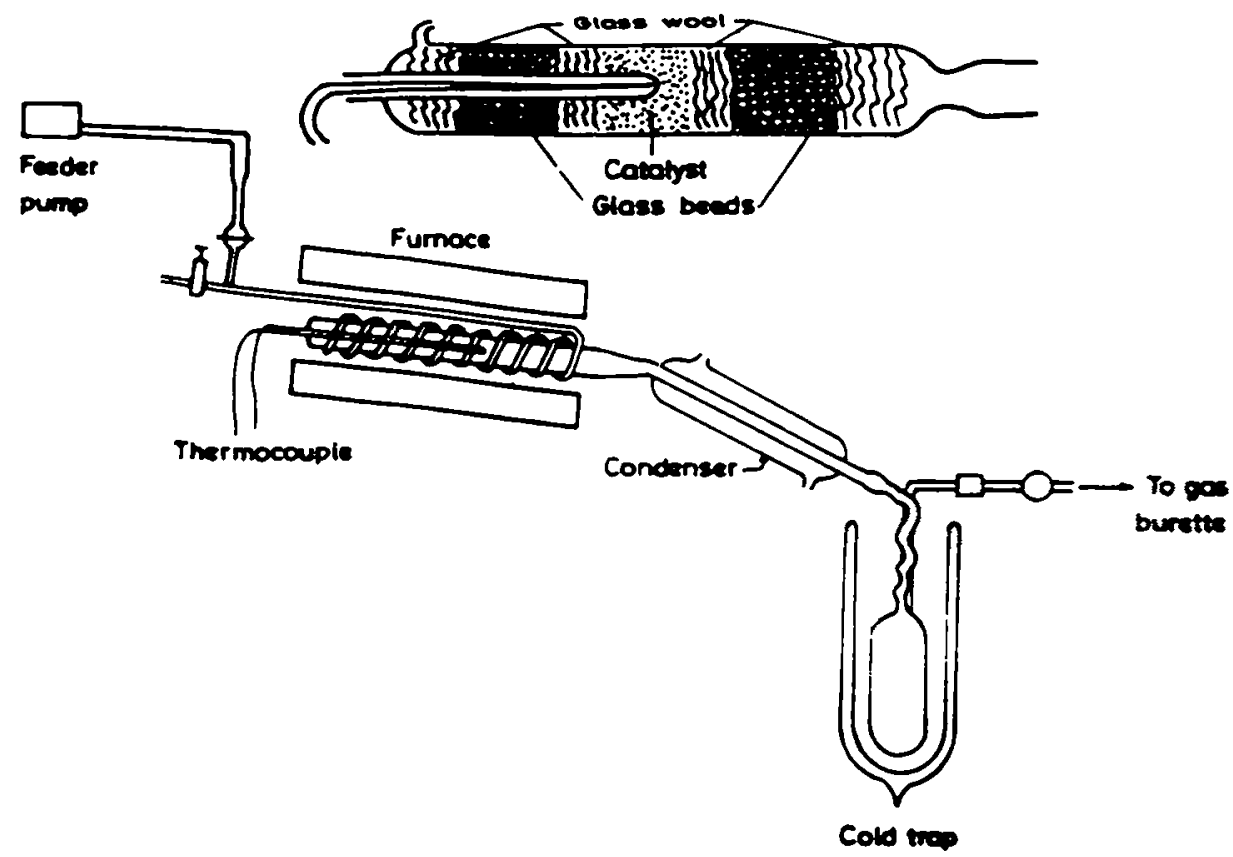

Figure 2. Flow-type reactor unit.

The time for which the reactants would sbe in contact with the catalyst is expressed as the time taken for the flow of the volume of the reactant equivalent to the volume of the catalyst at a particular temperature. The contact time is given by the following

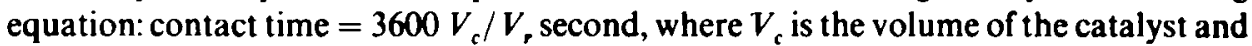
$V_{r}$ is the volume of the reactant in the vapour state flowing per hour at the reaction temperature. The duration of each experiment is usually 1 to $1 \frac{1}{2} \mathrm{~h}$. After a run is over, the apparatus is flushed with nitrogen to remove the remaining liquid from the catalyst chamber. Regeneration of the used catalyst is carried out by drawing a current of moisture-free air through the catalyst bed maintained at $350^{\circ} \mathrm{C}$ for $15 \mathrm{~h}$. This procedure for regeneration is found to restore the catalyst activity to its original level. The regenerated catalyst is used repeatedly for several reactions.

\subsection{Analysis of products}

Liquid products benzaldehyde, toluene and unreacted benzyl alcohol were analysed using a gas chromatograph (NETEL, Bombay), using 15\% carbowax on chromosorb W. A thermal conductivity detector was used with hydrogen as the carrier gas. The 
constituent products in the reaction mixture are identified by comparison with authentic samples of the suspected components. For quantitative analysis the method of internal normalisation is used where the relative response of the different com-pounds is determined by introducing exactly reproducible quantities of different substances into the unit.

\section{Results and discussion}

\subsection{Decomposition of benzyl alcohol}

Vapour phase reactions of benzyl alcohol have been carried out in a flow type reactor in the temperature range $250^{\circ} \mathrm{C}$ to $300^{\circ} \mathrm{C}$. No reaction takes place at $200^{\circ} \mathrm{C}$. This is possibly due to the high boiling point of benzyl alcohol $\left(202^{\circ} \mathrm{C}\right)$. At $350^{\circ} \mathrm{C}$ a black deposit is noticed inside the reactor during the decomposition of benzyl alcohol. Therefore a temperature range from $250^{\circ} \mathrm{C}$ to $300^{\circ} \mathrm{C}$ is chosen for conducting the reactions. The products formed are benzaldehyde, toluene, water and hydrogen.

\subsection{Effect of temperature and contact time}

The kinetics of decomposition of benzyl alcohol on copper aluminate was carried out to study the mechanistic aspects. Dehydrogenation of benzyl alcohol leads to the formation of benzaldehyde. Toluene is the other product formed. The mole percentage of benzaldehyde in the vapour phase is plotted against contact time at various temperatures (figure 3 ).

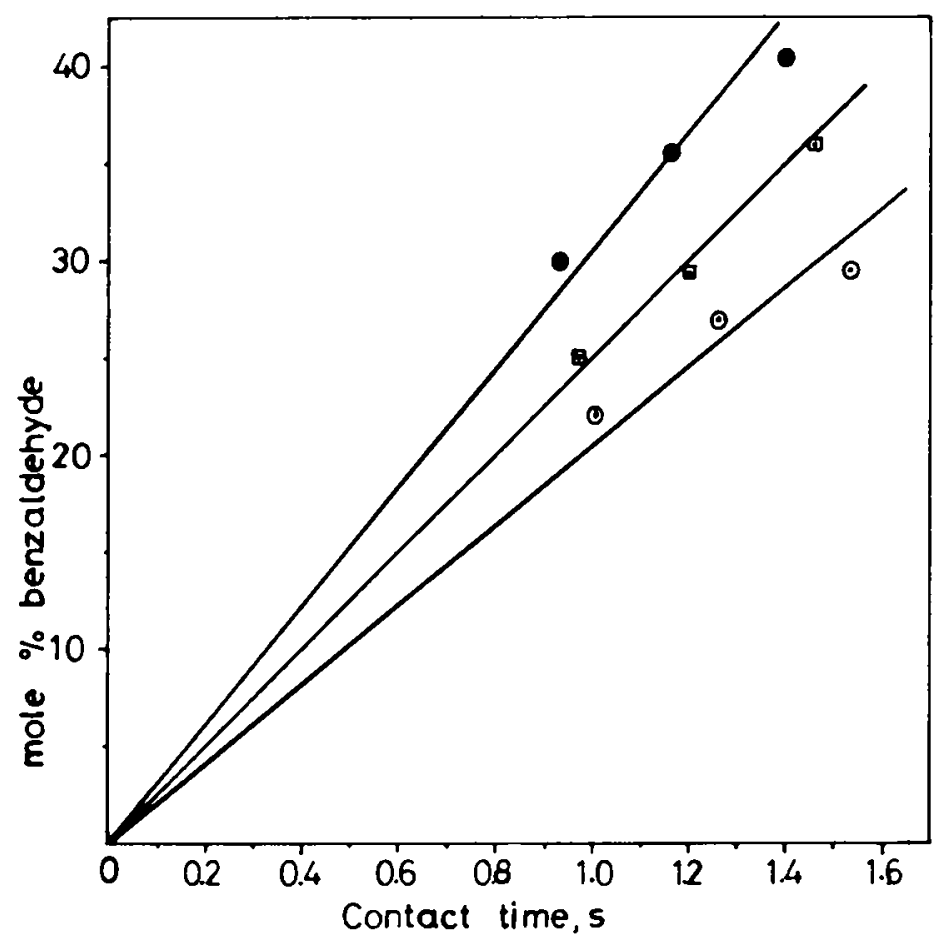

Figure 3. Plot of mole percent benzaldehyde vs contact time at various temperatures. 
The percentages of all the products, namely benzaldehyde, toluene, hydrogen and water are given in table 2 . The mass balance of the products and unreacted constituents has been checked and found to be within the limits of reasonable experimental error. The rate of dehydrogenation at any particular temperature is obtained from the initial slopes of percent mole of benzaldehyde formed versus contact time plots. The benefit of using the initial rates for computing the kinetic parameters lies in the fact that it avoids any possible influence of the products of the reaction on the rate. Logarithms of these initial rates are plotted against the reciprocal temperatures to get the Arrhenius plot (figure 4). From the slope of this plot the activation energy for the dehydrogenation reaction is obtained. Note that activation energy values obtained are only apparent and not true values. The true activation energy values can be obtained only at equal coverages of the surface of the catalyst. The coverage of the catalyst cannot be assumed to be constant at the various temperatures studied. It is found that the rates of formation of benzaldehyde increased regularly with temperature and there were no breaks in the Arrhenius plots. This would suggest that there are no changes in the nature of the active centres in the temperature range studied. The initial rates calculated at various temperatures on plotting against reciprocal temperature give a straight line and the activation energy is found to be $21 \cdot 25 \mathrm{~kJ} / \mathrm{mol}$.

\subsection{Mechanism for the decomposition of benzyl alcohol}

Formation of benzaldehyde can be explained by either dehydrogenation or disproportionation of benzyl alcohol. Formation of toluene and water can be explained by either disproportionation of benzyl alcohol,

$$
2 \mathrm{C}_{6} \mathrm{H}_{5} \mathrm{CH}_{2} \mathrm{OH} \rightarrow \mathrm{C}_{6} \mathrm{H}_{5} \mathrm{CHO}+\mathrm{C}_{6} \mathrm{H}_{5} \mathrm{CH}_{3}+\mathrm{H}_{2} \mathrm{O} \text {, }
$$

or by hydrogenolysis of benzyl alcohol by adsorption of hydrogen.

$$
\mathrm{C}_{6} \mathrm{H}_{5} \mathrm{CH}_{2} \mathrm{OH}+\mathrm{H}_{2} \rightarrow \mathrm{C}_{6} \mathrm{H}_{5} \mathrm{CH}_{3}+\mathrm{H}_{2} \mathrm{O} \text {. }
$$

Jayamani and Pillai (1983) showed that acidic disproportionation sites are the active sites with respect to the reaction of benzyl alcohol using alumina as the catalyst. They also suggest a hydride transfer mechanism for decomposition of benzyl alcohol. In the

Table 2. Effect of temperature and contact time on decomposition of benzyl

\begin{tabular}{|c|c|c|c|c|c|c|c|c|}
\hline \multirow[b]{2}{*}{$\begin{array}{l}\mathrm{T} \\
\left({ }^{\circ} \mathrm{C}\right)\end{array}$} & \multirow{2}{*}{$\begin{array}{c}\text { Flow } \\
\text { rate } \\
\left(\mathrm{cm}^{3} / \mathrm{h}\right)\end{array}$} & \multirow[b]{2}{*}{$\begin{array}{l}\text { Contact } \\
\text { time(s) }\end{array}$} & \multicolumn{4}{|c|}{ Products in the vapour phase (\%) } & \multirow{2}{*}{$\begin{array}{c}\text { Unreacted } \\
\mathrm{C}_{6} \mathrm{H}_{5}^{-} \\
\mathrm{CH}_{2} \mathrm{OH} \\
(\%)\end{array}$} & \multirow{2}{*}{$\begin{array}{c}\text { Amt. of } \\
\mathrm{C}_{6} \mathrm{H}_{5}^{-} \\
\mathrm{CHO} \\
(\text { Mole \%) }\end{array}$} \\
\hline & & & $\begin{array}{c}\mathrm{C}_{6} \mathrm{H}_{5-} \\
\mathrm{CHO}\end{array}$ & $\underset{\mathrm{CH}_{3}}{\mathrm{C}_{6} \mathbf{H}_{5}-}$ & $\mathbf{H}_{2}$ & $\mathrm{H}_{2} \mathrm{O}$ & & \\
\hline 250 & $27 \cdot 8$ & 1.02 & $38 \cdot 0$ & 300 & 0.72 & 5.9 & $25 \cdot 4$ & $22 \cdot 3$ \\
\hline 250 & $22 \cdot 5$ & 1.26 & $47 \cdot 6$ & 27.0 & 0.90 & 5 & $19 \cdot 2$ & 27.0 \\
\hline 250 & 18.5 & 1.53 & 52.0 & 24.0 & 0.98 & $4 \cdot 7$ & $18 \cdot 3$ & $29 \cdot 4$ \\
\hline 275 & 27.8 & 0.97 & 43.0 & 240 & 0.81 & $4 \cdot 7$ & 27.5 & 25.6 \\
\hline 275 & 22.5 & $1 \cdot 20$ & 520 & 22.0 & 0.98 & 43 & 20.7 & $29 \cdot 3$ \\
\hline 275 & 18.5 & 1.46 & 650 & 200 & $1 \cdot 23$ & 3.9 & 9.9 & 350 \\
\hline 300 & $27 \cdot 8$ & 0.93 & $52 \cdot 0$ & 200 & 0.98 & 3.9 & $23 \cdot 1$ & 30.1 \\
\hline 300 & $22 \cdot 5$ & $1 \cdot 16$ & 65.0 & $17 \cdot 0$ & 1.23 & $3 \cdot 3$ & 13.5 & $35 \cdot 6$ \\
\hline 300 & 18.5 & 1.40 & $78-0$ & 15.0 & 1.47 & 2.9 & $2 \cdot 6$ & 40.5 \\
\hline
\end{tabular}
alcohol. 


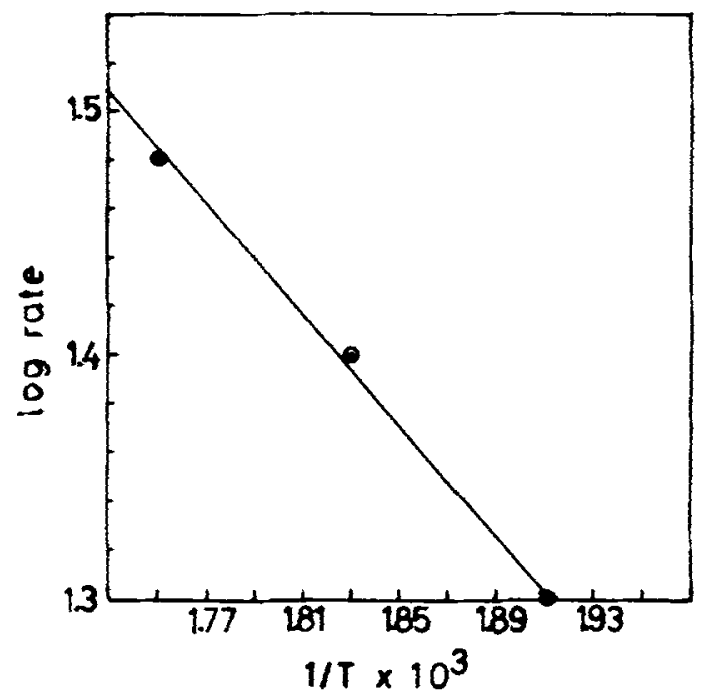

Figare 4. Arrhenius plot.

present study with copper aluminate, acidic sites are negligible as seen from surface acidity studies using $n$-butyl amine as the base for adsorption. Therefore, a hydride transfer mechanism can be ruled out. Formation of benzaldehyde by a disproportionation route can also be ruled out. Moreover, copper aluminate is a well-known dehydrogenating agent (Ramalingam and Swamy 1978; Venkatasubramanian 1979). Hence, formation of benzaldehyde can be explained by a dehydrogenation route. The copper in copper aluminate is probably the active site for dehydrogenation of benzyl alcohol since aluminium does not change its oxidation state readily (Murthy 1991).

With a view to understanding the influence of the products on the kinetics of dehydrogenation of benzyl alcohol, studies are conducted at $250^{\circ} \mathrm{C}$ by mixing various proportions of benzaldehyde with benzyl alcohol (figure 5). Benzaldehyde strongly inhibits the dehydrogenation of benzyl alcohol as well as the formation of toluene. Desorption of benzaldehyde can be considered the rate-determining step in the mechanism. The following scheme can be suggested for the hydrogenation of benzyl alcohol.

$$
\begin{aligned}
\mathrm{C}_{6} \mathrm{H}_{5} \mathrm{CH}_{2} \mathrm{OH}_{\text {(vapour) }} & \rightleftharpoons \mathrm{C}_{6} \mathrm{H}_{5} \mathrm{CH}_{2} \mathrm{OH}_{\text {(ndsarbed) }} \\
\mathrm{C}_{6} \mathrm{H}_{5} \mathrm{CH}_{2} \mathrm{OH}_{\text {(adsorbed) }} & \rightleftharpoons \mathrm{C}_{6} \mathrm{H}_{5} \mathrm{CHO}_{\text {(adsorbed) }}+2 \mathrm{H}_{\text {(adsarbed) }} \\
2 \mathrm{H}_{\text {(adsarbed) }} & \rightleftharpoons \mathrm{H}_{2(\mathrm{gas})} \\
\mathrm{C}_{6} \mathrm{H}_{5} \mathrm{CHO}_{\text {(edsorbed) }} & \rightleftharpoons \mathrm{C}_{6} \mathrm{H}_{5} \mathrm{CHO} \mathrm{O}_{\text {(vapour) }}
\end{aligned}
$$

Hydrogenolysis of benzyl alcohol was suggested for the formation of diphenyl methane at $400^{\circ} \mathrm{C}$ using alumina as the catalyst (Unni et al 1973). In the present study experiments were conducted to study the effect of passing hydrogen along with the reactants. It is found that the amount of toluene formed increased from $19 \%$ to $30 \%$ when hydrogen gas was passed along with benzyl alcohol. This indicates that direct hydrogenolysis of benzyl alcohol leading to the formation of toluene probably takes 


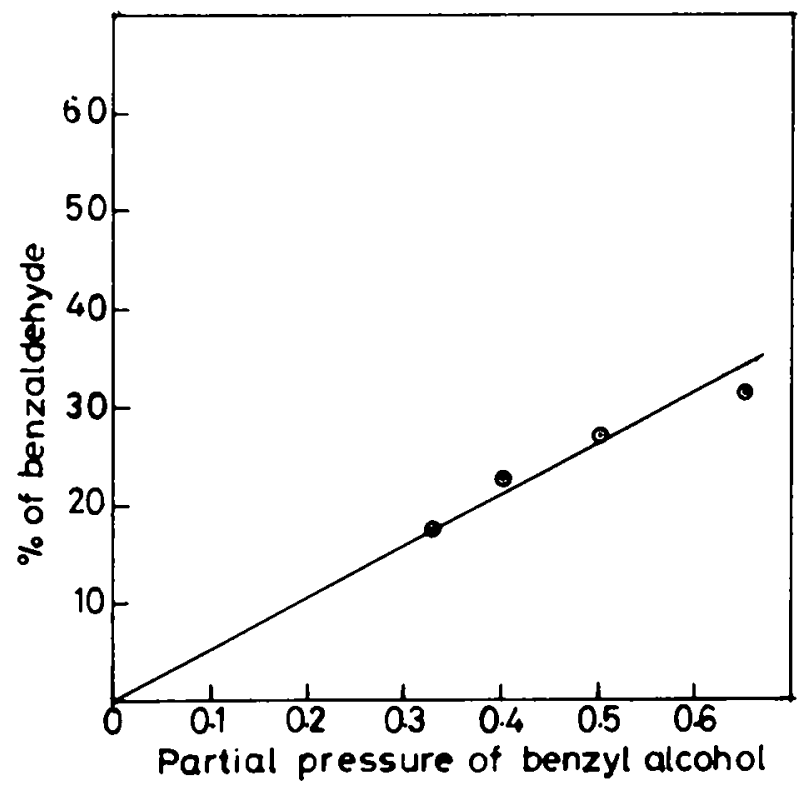

Figure 5. Plot of percentage of benzaldehyde vs partial pressure of benzyl alcohol.

place. A similar conclusion was arrived at in transfer hydrogenation reaction using benzyl alcohol and acetone (Venkatachalam and Kuriacose 1971), and using ethyl alcohol on chromia as the catalyst (Pandao et al 1962). Based on the above discussion the formation of benzaldehyde and toluene can be given by the following routes.

$$
\begin{aligned}
& \mathrm{C}_{6} \mathrm{H}_{5} \mathrm{CH}_{2} \mathrm{OH} \rightarrow \mathrm{C}_{6} \mathrm{H}_{5} \mathrm{CHO}+\mathrm{H}_{2}, \\
& \mathrm{C}_{6} \mathrm{H}_{5} \mathrm{CH}_{2} \mathrm{OH}+\mathrm{H}_{2} \rightarrow \mathrm{C}_{6} \mathrm{H}_{5} \mathrm{CH}_{3}+\mathrm{H}_{2} \mathrm{O} .
\end{aligned}
$$

\section{Acknowledgements}

The authors wish to thank the management of St. Joseph's College, Bangalore for encouragement. Thanks are also due to Mr A Muthuswamy, Mr S Selvaraj and Ms Bharathi Manjunath. VS wishes to thank the University Grants Commission, New Delhi for financial assistance.

\section{References}

Jayamani M and Pillai C M 1983 J. Catal. 82485

Ketchik S V, Plyasova L M, Seredkin A E, Kostrov U V and Morozov L N 1980 React. Kinet. Catal. Lett. 14429

Krishnaswamy V and Chokkalingam S 1982 J. Indian Chem. Soc. 59641

Kushnerev M Ya, Linde V R, Roginskii S Z and Tverdogo F 1961 Tela 3384

Massoth F E and Scarpiello D A 1971 J. Catal. 21294

Murthy I A P S 1991 Physico-chemical and catalytic studies on some spinels and systems derived from spinels and intermetallics, $\mathrm{Ph} \mathrm{D}$ thesis, Indian Institute of Technology, Madras

Paetour H and Reikert Z 1979 Ber. Bunsenges. Phys. Chem. 83807 
Pandao S N, Kuriacose J C and Sastri M V C 1962 J. Sci. Ind. Res. D21 180

Piperov B and Mekhandzhiev D 1987 Izv. Khim. 20500

Ramalingam T and Swamy C S 1978 Proceedings of fourth national symposium on catalysis (Bombay: Catalysis Society of India) p. 244

Unni M P K, Santhanagopalan S and Pillai C N 1973 J. Indian Chem. Soc. 50582

Venkatachalam R and Kuriacose J C 1971 J. Indian Chem. Soc. 48206

Venkatasubramanian N 1979 Mechanistic studies of reactions of glcohols on pure and sodium ion doped alumina catalysts, $\mathrm{Ph} \mathrm{D}$ thesis, Indian Institute of Technology, Madras

Viswanathan B, Krishnamoorthy K R and Sastri M V C 1979 J. Res. Inst. Catal. 2779

Zanderighi I, Faedda M P and Carra S 1974 J. Catal. 35427 